\section{Analisis Determinasi Tingkat Net Core Operational Margin Pada Bank Umum Syariah Di Indonesia}

\author{
Komarudin*, Ayus A hmad Yusuf \\ IAIN Syekh Nurjati Cirebon, Indonesia
}

\begin{abstract}
A bstract
Purpose- The purpose of this study is to explore the impact of bank's internal and external factors on net core operational margin in Indonesia's Islamic commercial banks companies.

Methods- A quantitative approach by using panel data regression with a periode from 2nd quarter 2010 to 2 nd quarter 2015. The object of this study is eight Islamic commercial banks companies which were listed in sharia bank directory of Central Bank of Indonesia and Financial Services Authority of Republic of Indonesia. The model of estimation which is used, is the model of panel data namely cross-sectional time series feasible generalized least square.

Findings- This study can be concluded that capital adequacy ratio and average operational cost have a positive and significant impact on net core operational margin. On the contrary, financing to deposit ratio, bank size, operational efficiency ratio and $\mathrm{BI}$ rate have a negative and significant impact on net core operational margin.

Research implications- The management needs to create an efficient banking system by reducing operational costs and improving management quality. Banks are also advised to increase the prudential principle in managing finance so that the risk of default can be minimized.
\end{abstract}

Keywords Internal Factors, External Factor, $\mathrm{N}$ et Core $\mathrm{O}$ perational $\mathrm{M}$ argin Paper type Research paper

Email korespondensi: komarudin.mepi3@gmail.com

\section{Pedoman Sitasi}

Komarudin \& Ayus A hmad Yusuf (2019). Analisis Determi nasi Tingkat Net Core Operational Margin Pada Bank Umum Syariah di Indonesia . SERAMBI, 1(2), 21 - 32

D 0I: https:/ / doi.org/ 10.36407/ serambi.v1i2.68

\section{SERAM BI}

Received 24 May 2019

Revised 12 Jun 2019

Accepted 20 Jul 2019 


\section{Pendahuluan}

Indonesia menerapkan istem perbankan dual banking system, artinya terdapat bank yang beroperasi menggunakan sistem konvensional dan bank yang beroperasi menggunakan sistem syariah. Dengan dibentuknya legalitas hukum perbankan syariah dalam Undang-undang Nomor 21 Tahun 2008 tentang Perbankan Syariah, telah memberikan dukungan yang besar bagi dunia bisnis syariah di Indonesia, dengan mempunyai prinsip islam dalam kegiatan operasional yang tidak didasarkan pada sistem bunga, melainkan atas prinsip syariah. Pertumbuhan perbankan syariah di Indonesia mengalami perkembangan yang cukup signifikan. Banyak perbankan konvensional yang membuka unit yang melaksanakan kegiatan usaha berdasarkan prinsip syariah, hingga akhirnya spin- off menjadi Bank Umum Syariah. Pada periode Juni 2015, Bank Umum Syariah berjumlah 12 bank, Unit Usaha Syariah berjumlah 22 bank dan Bank Pembiayaan Rakyat Syariah berjumlah 161 bank.

Perkembangan industri perbankan syariah di Indonesia dapat juga dilihat dari pertumbuhan aset, pembiayaan dan dana pihak ketiga yang berhasil dihimpun. Jumlah aset perbankan syariah di Indonesia pada Juni tahun 2015 mengalami peningkatan sebesar 1204,54 \% apabila dibandingkan dengan jumlah aset perbankan syariah pada akhir tahun 2005, yaitu dari Rp. 20.880 miliar menjadi Rp. 272.389 miliar. Pada sisi pembiayaan, dana yang telah disalurkan perbankan syariah meningkat sebesar 1235,26 \% atau dari sebesar Rp. 15.270 miliar (2005) menjadi Rp. 203.894 miliar (Juni 2015). Demikian pula dengan jumlah dana pihak ketiga (DPK) yang berhasil dihimpun perbankan syariah di Indonesia, mengalami peningkatan sebasar 1280,99 \% dari Rp. 15.593 miliar pada akhir tahun 2005 menjadi Rp. 215.339 miliar pada Juni tahun 2015. Dari angka pertumbuhan tersebut, maka pertumbuhan dana pihak ketiga (DPK) dalam bentuk giro, tabungan dan deposito dalam kurun waktu hingga Juni 2015 mengalami pertumbuhan yang paling tinggi, bila dibandingkan dengan pertumbuhan aset dan pertumbuhan penyaluran pembiayaan.

Dalam memenuhi tugasnya sebagai agen pembagunan, perbankan dituntut untuk menjalankan fungsi intermediasinya dengan biaya yang efisien guna meningkatkan pertumbuhan ekonomi. Biaya intermediasi keuangan dapat diukur dengan selisih pendapatan bersih dari operasi utama terhadap total penyaluran dana (tingkat net core operational margin). Semakin rendah tingkat net core operational margin yang didapat, maka akan semakin rendah biaya intermediasi keuangan. Biaya intermediasi yang efisien dapat merefleksikan efektivitas kebijakan moneter bank sentral, terjaganya stabilitas keuangan dan sistem perbankan yang kompetitif. Sebaliknya, biaya intermediasi yang tinggi akan mengurangi insentif bagi para pelaku ekonomi.

Pada beberapa negara dimana bank merupakan sumber utama dalam penggerak roda perekonomian, tingkat net core operational margin merupakan salah satu variabel utama untuk mengukur seberapa efisien bank menjalankan fungsinya sebagai lembaga intermediasi, dalam rangka peningkatan taraf hidup rakyat banyak. Disisi lain, tingkat net core operational margin merupakan salah satu rasio keuangan yang digunakan untuk mengukur tingkat profitabilitas bank. Semakin tinggi tingkat net core operational margin merefleksikan tingkat keuntungan bank yang semakin tinggi dan stabilitas perbankan semakin terjaga. Oleh sebab itu, terdapat konflik kepentingan antara biaya intermediasi yang diharapkan rendah dengan profitabilitas yang harus dicapai perbankan.

Dalam rangka menghadapi era Masyarakat Ekonomi ASEAN (MEA) yang akan dimulai pada tahun 2015 untuk sektor non keuangan dan tahun 2020 untuk sektor perbankan dan keuangan, perbankan di Indonesia harus mulai meningkatkan efisiensi guna menghadapi persaingan global dengan perbankan di negara kawasan ASEAN yang telah memiliki efektivitas terstrukur dan rendahnya suku bunga kredit. Dengan memiliki daya saing yang tinggi, khususnya perbankan syariah di Indonesia, diharapkan dapat memperluas dan memasuki pasar keuangan dan perbankan di negara-negara lain, khusunya negara-negara di kawasan ASEAN .

Tulisan ini menjelaskan tentang gambaran mengenai pengaruh faktor internal terhadap tingkat net core operational margin dan menjelaskan gambaran mengenai pengaruh faktor eksternal bank 
terhadap tingkat net core operational margin pada Bank Umum Syariah di Indonesia dan faktor yang manakah yang paling besar mempengaruhi tingkat net core operastional margin. Dengan mengetahui secara tepat faktor yang mempengaruhi net core operational margin Bank Umum Syariah di Indonesia, diharapkan menjadi acuan bagi industri perbankan syariah dalam menjaga kestabilan tingkat net core operational margin Bank Umum Syariah di Indonesia di masa datang.

\section{Literature Review}

Tingkat $\mathrm{N}$ et $\mathrm{C}$ ore $\mathrm{O}$ perational $\mathrm{M}$ argin ( $\mathrm{N}$ et Interest $\mathrm{M}$ argin)

Analisis NCOM ( $\mathrm{N}$ et Core O perational M argin) merupakan salah satu cara dalam mengukur biaya intermediasi keuangan, yaitu selisih antara biaya bunga yang dibayar peminjam kepada bank dan pendapatan bunga yang diterima deposan. Tingkat net core operational margin disini diartikan sebagai net interest margin sebuah istilah dalam perbankan konvensional yang menggambarkan selisih antara pendapatan bunga dengan biaya bunga sebagai bagian atau proporsi dari total aset atau aktiva produktif bank. Dalam perbankan syariah istilah NIM dikenal juga dengan istilah net core operational margin. Biaya intermediasi keuangan yang efisien yang ditunjukan dengan rendahnya margin perbankan akan merefleksikan keefektifan kebijakan moneter, kestabilan keuangan dan sistem perbankan yang berjalan secara kompetitif. Disisi lain, tingginya biaya intermediasi keuangan akan mereduksi insentif bagi para pelaku ekonomi.

Studi mengenai faktor penentu NCOM dapat dibagi menjadi dua model kerangka kerja. Model pertama dipelopori oleh Ho dan Saunders (1981). Model Ho dan Saunders menjelaskan bahwa bank berperan sebagai dealer yang menetapkan bagi hasil (suku bunga) dalam pinjaman dan deposit. Bank akan selalu menghadapi ketidakpastian dan biaya karena permintaan pinjaman dan penyediaan simpanan bersifat skolastik, sehingga kedua unsur utama tersebut akan berada di dalam tiba dalam waktu yang berbeda. Dengan demikian, bank akan menyediakan posisi jangka panjang dan jangka pendek dalam pasar uang untuk dapat menyeimbangkan ketidakpastian yang timbul karena risiko suku bunga dan mempengaruhi tingkat net core operational margin.

Model kedua dikembangkan oleh Klein (1971) dan Monti (1972). Model kedua ini menguji bank sebagai model yang memiliki sifat statis antara penyediaan deposit dan permintaan pinjaman. Pendekatan kedua menganalisis perbankan dengan keadaan statis dimana permintaan pinjaman dan suplai dari deposit secara simultan. Pendekatan mikrostatis dikembangkan dari kritik bahwa dealership approach gagal mempertimbangkan beberapa aspek yang relevan dalam kegiatan operasional bank, seperti biaya administratif untuk mengelola kontak pinjaman dan deposit dan strukur kelembangaan pasar perbankan.

D eterminasi $\mathrm{N}$ et Core O perational M argin Pada Bank Syariah

Pada dasarnya tingkat net core operational margin pada Bank Syariah ditentukan oleh sifat dari komponennya. Bank Syariah tidak pernah menetapkan komitmen sebelumnya untuk membayar pendapatan atau keuntungan kepada para deposan baik dalam jumlah nominal maupun dalam presentase, karena hal ini melanggar aturan syariah. Demikian pula, persentase pada deposit maupun pembiayaan pada produk berdasarkan hutang pada Bank Syariah diketahui ex ante, sedangkan produk berdasarkan modal diketahui ex post. Seluruhnya, pendapatan deposit dan pembiayaan yang menggunakan produk berdasarkan modal dalam Bank Syariah akan diketahui ex post.

Kerangka Konseptual dan Hipotesis Penelitian

Hubungan Capital A dequacy Ratio dengan $\mathrm{N}$ et Core $\mathrm{O}$ perational $\mathrm{M}$ argin

Fungacova dan Poghosyan (2007) menganalisis determinasi interest margin sektor perbankan Rusia dengan penekanan pengaruh stuktur kepemilikan bank. Hasil analisis mengkonfirmasi terhadap interest margin bahwa rasio permodalan berpengaruh positif dan signifikan, namun risiko liquiditas 
dan risiko kedit berpengaruh negatif dan signifikan dengan interest margin. Temuan lainnya menyatakan bahwa koefisien biaya operasional dan rasio permodalan memiliki pengaruh positif dan signifikan pada semua model berdasarkan kepemilikan. Pada model kepemilikan bank asing, struktur pasar dan ukuran operasional berpengaruh positif dan signifikan. Pengaruh negatif dan signifikan pada risiko kredit hanya ditemukan dalam model bank milik swasta. Selanjutnya risiko likuiditas memiliki pengaruh negatif signifikan pada interest margin bank milik swasta.

Dumicic dan Ridzak (2012) hasil penelitian menunjukan, kenaikan efisiensi berkontribusi terhadap penurunan net interest margin, perkembangan reservation berpengaruh negatif terhadap net interest margin. Rasio net loan to total assets berpengaruh positif, terhadap net interest margin. Capital adequacy ratio berpengaruh positif terhadap net interest margin. Berbagai variabel non bank yaitu suku bunga domestik jangka pendek, volatilitas suku bunga, hutang pemerintah (persentase dari PDB), pertumbuhan PDB, dan defisit anggaran berjalan, dalam periode pra-krisis berpengaruh signifikan terhadap net interest margin diantaranya level. Namun, dalam periode krisis, tidak ada satupun variabel makroekonomi yang berpengaruh signifikan terhadap net interest margin.

Hubungan Financing to $\mathrm{D}$ eposit Ratio dengan $\mathrm{N}$ et Core $\mathrm{O}$ perational $\mathrm{M}$ argin

Hasil penelitian Irwan, Agusman dan Tarazi (2003), membuktikkan bahwa portofolio pinjaman merupakan determinasi interest margin. Kekuatan pasar yang diukur dengan lerner indeks, berpengaruh positif terhadap interest margin. Variabel cross-subsidization strategy dalam diversifikasi pendapatan berpengaruh negatif signifikan pada semua model regresi. Rasio biaya operasional terhadap total aset berpengaruh positif dan signifikan terhadap net interest margin. Ukuran bank yang diproksi dengan logaritma natural dari total aset berpengaruh negatif terhadap NIM. Rasio equitas terhadap total aset yang merupakan proksi dari risk aversion berpengaruh positif dan signifikan pada semua model regresi. Risiko kredit yang diukur dengan rasio non performing loan terhadap total pinjaman, memiliki pengaruh negatif dan signifikan terhadap net interest margin. Perbandingan pinjaman terdapat total dana pihak ketiga sebagai proksi risiko likuiditas memiliki pengaruh negatif terhadap NIM.

Hubungan Bank Size dengan $\mathrm{N}$ et $\mathrm{C}$ ore $\mathrm{O}$ perational $\mathrm{M}$ argin

Bennaceur dan Goaied (2000), telah membuktikkan hasil penelitian bahwa, equity to total assets ratio, total kewajiban dan overhead to total assets berpengaruh positif dan signifikan terhadap net interest margin dan profitabilitas (return on assets). Ukuran bank berpengaruh negatifdan signifikan terhadap net interest margin dan profitabilitas. Variabel pertumbuhan makroekonomi yang diproksi PDB riil perkapita tidak berpengaruh terhadap profitabilitas perbankan serta pertumbuhan pasar modal memiliki pengaruh positif terhadap net interest margin dan profitabilitas.

Hubungan A verage $O$ perational Cost dengan $\mathrm{N}$ et Core $O$ perational $\mathrm{M}$ argin

Ugur dan Erkus (2007) hasil regresi pertama menujukan terdapat hubungan negatif dan signifikan antara market share dan net interest margin. Ukuran bank, biaya operasional dan rasio modal secara parsial berpengaruh positif dan signifikan terhadap net interest margin. Sedangkan, kualitas management berpengaruh negatif dan signifikan terhadap net interest margin. Pada tahap kedua, pure spreads diregresikan dengan beberapa variabel makroekonomi. Berdasarkan hasil dari regresi, hanya tingkat inflasi yang berpengaruh positif signifikan untuk menjelaskan pure spread.

Sidabalok dan Viverita (2009), hasil penelitian menunjukan, operating cost dan risiko kredit secara parsial berpengaruh positif dan signifikan terhadap net interest margin. Tanda positif dan signifikan juga terlihat dari hubungan antara net interest margin dengan risk aversion. Besarnya kegiatan operasional bank dan efisiensi yang menunjukan kualitas manajemen bank secara parsial berpengaruh negatif signifikan terhadap net interest margin. Rasio hutang bank berpengaruh positif 
Komarudin \& Ayus A hmad Yusuf / Analisis Determninasi Tingkat...

dan signifikan terhadap net interest margin. Dalam penelitian ini, seluruh variabel makroekonomi seperti pertumbuhan produk domestik bruto, inflasi, dan nilai tukar Rupiah terhadap Valuta Asing, tidak berpengaruh terhadap net interest margin.

Hubungan O perational Effeciency Ratio dengan $\mathrm{N}$ et $\mathrm{C}$ ore O perational $\mathrm{M}$ argin

Ascarya dan Yumanita (2009), hasil penelitian menunjukan bahwa, beberapa variabel faktor internal yaitu default risk, liquidity risk, operational cost, efficiency, operational policy, opportunity cost of bank reserve, strategy of cross subsidy, market structure berpengaruh positif dan signifikan terhadap net interest margin. Sedangkan varibel implicit cost, size, incomefrom trading, ratio of deposit, non performing loan berpengaruh negatif dan signifikan terhadap net interest margin. Inflasi dan market rate pasar uang antar bank yang merupakan faktor eksternal berpengaruh negatif signifikan terhadap net interest margin, sebaliknya interest market volatility dan growth of GDP berpengaruh positif signifikan terhadap net interest margin.

Hubungan Finance Risk dengan $\mathrm{N}$ et Core 0 perational $\mathrm{M}$ argin

Joaquin dan Guevara (1993) hasilnya menunjukkan bahwa Lerner Index berpengaruh positif terhadap interest margin dan memiliki tingkat signifikansi yang tinggi. Risiko tingkat suku bunga juga menunjukan tanda positif, menunjukan asumsi, dimana perbankan yang beroperasi pada risiko pasar yang besar akan menetapkan interest margin lebih tinggi. Risk aversion menunjukan pengaruh positif. Variabel biaya operasi berpengaruh positif terhadap interest margin. Kualitas manajemen menunjukan pengaruh negatif (tingginya nilai variabel ini berarti rendahnya efisiensi dalam perusahaan) dengan tingkat signifikansi yang tinggi. Implicit payment menujukan pengaruh positif, Dalam kasus ini variabel opportunity cost of reserve, menujukan pengaruh positif, akan tetapi secara statistik tidak signifikan.

Hubungan $\mathrm{BI}$ Rate dengan $\mathrm{N}$ et Core $\mathrm{O}$ perational $\mathrm{M}$ argin

Hasil penelitian Hutapea dan Kasri (2006) berkesimpulan bahwa bank syariah menunjukan respon positif margin bank pada risiko gagal bayar, solvecy ratio, biaya-biaya implisit dan biaya peluang dari cadangan bank. Sebaliknya, margin bank bereaksi negatif pada volatilitas suku bunga, kualitas manajemen dan risiko likuiditas. Secara umum, semua variabel bebas memiliki tanda yang sama. Hanya variabel volatilitas suku bunga yang memiliki pengaruh yang berbeda. Pengaruh negatif ditemukan pada perbankan syariah, sedangkan pada perbankan konvensional ditemukan arah yang berlawanan.

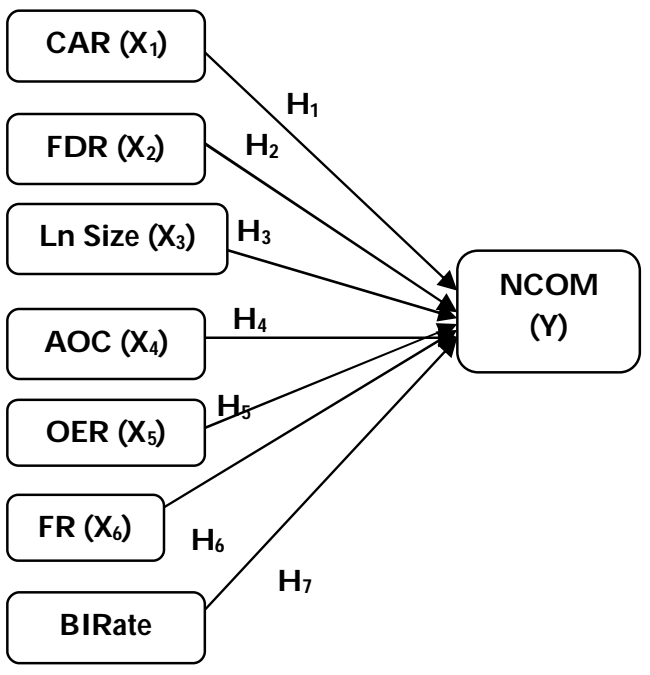

G ambar 1. Kerangka Konseptual 


\section{Metodologi Penelitian}

Data penelitian merupakan data sekunder yang diperoleh melalui lembaga Otoritas Jasa Keuangan (OJK) untuk Bank Umum Syariah. Penelitan ini menggunakan kriteria teknik pengambilan sampling yang teridiri dari delapan (8) Bank Umum Syariah dengan data keuangan berdasarkan laporan quartal per tahunnya, dan total observasi yaitu 166 data yang akan diolah. Analisis data yang dilakukan melalui program statistik yaitu Eviews.

Teknik A nalisis D ata

Teknik analisis data yang digunakan dalam penelitian ini adalah menggunakan teknik analisis regresi data panel. Data panel sering disebut pool ed data (merupakan kombinasi antara data yang bersifat time series dan cross-section), micropanel data, longitudinal data, event history analysis atau cohort analysis. Dalam data panel, unit cross-section yang sama (keluarga atau perusahaan atau negara) diteliti selama periode waktu tertentu. Sehingga dapat disimpulkan data panel merupakan data yang memiliki dimensi time series maupun cross section.

Analisis regresi yang dilakukan menggunakan pendekatan dari data panel, dalam hal ini menggunakan tiga pendekatan utama antara lain: pool ed least square, fixed effect model, dan random effect model. Model yang dihasilkan dari pendekatan-pendekatan tersebut kemudian dipilih sesuai dengan pengujian statistik dan kecocokan model dengan karakteristik data. Pengujian dan pemilihan model dalam regresi data panel digunakan untuk memilih model yang lebih sesuai dan memiliki pendugaan yang lebih efisien. Berikut adalah persamaan regresi pada model penelitian sebagai berikut:



\section{Hasil dan Pembahasan}

Pengujian dan pemilihan model dalam regresi data panel digunakan untuk memilih model yang lebih sesuai dan memiliki pendugaan yang lebih efisien. Ada beberapa teknik pengujuan statistika dalam pemilihan model pada data panel, diantaranya adalah Ftest dan hausman test. Ftest digunakan untuk membandingkan pemilihan model antara pooled least square dengan fixed effect model. Sedangkan hausman test digunakan untuk membandingkan pemilihan model antara fixed effect model dengan random effect model.

Pengujian pertama yang dilakukan adalah Ftest guna memilih model antara pooled least square dan fixed effect model. Hasil Uji F-test menunjukan nilai dari Ftest memberikan hasil yang signifikan, yaitu nilai probability sebesar 0,0000 <5\% (0.05). Sehingga kesimpulan yang dapat diambil adalah model yang digunakan mengikuti fixed effect model (FEM). Pengujian kedua adalah hausman test yang digunakan untuk memilih model antara fixed effect model (FEM) dan random effect model (REM). Dari hasil pengujian hausman yang dilakukan, terlihat bahwa pada hasil tersebut memiliki Prob > chi2 sebesar lebih kecil dari $5 \%$ artinya memberikan hasil yang signifikan, sehingga model yang digunakan 
mengikuti fixed effect model (FEM). Berdasarkan pengujian Ftest dan pengujian hausman yang telah dilakukan, pemilihan model antara pooled least square, fixed effect model, dan random effect model. Maka disimpulkan bahwa model yang paling sesuai dan memiliki pendugaan yang lebih efisien adalah fixed effect model.

Hasil Probalitas Wald chi square memiliki nilai 0, yang menunjukan bahwa secara bersama-sama koefisien regresi memiliki nilai yang signifikan, artinya variabel bebas secara bersama-sama memiliki pengaruh terhadap variabel terikat. Sehingga dapat dikatakan bahwa model yang digunakan cukup baik. Nilai $R^{2}$ memiliki nilai 0,3456 yang menunjukan bahwa tingkat determinasi dari variabel bebas terhadap variabel terikat adalah sebesar 34,56 \%. Artinya sebesar 34,56\% variabilitas dari NCOM dapat dijelaskan oleh variabel-variabel bebas.

Tabel 1. H asil Regesi Cross-Sectional Time Series Feasible Generalized Least Squares

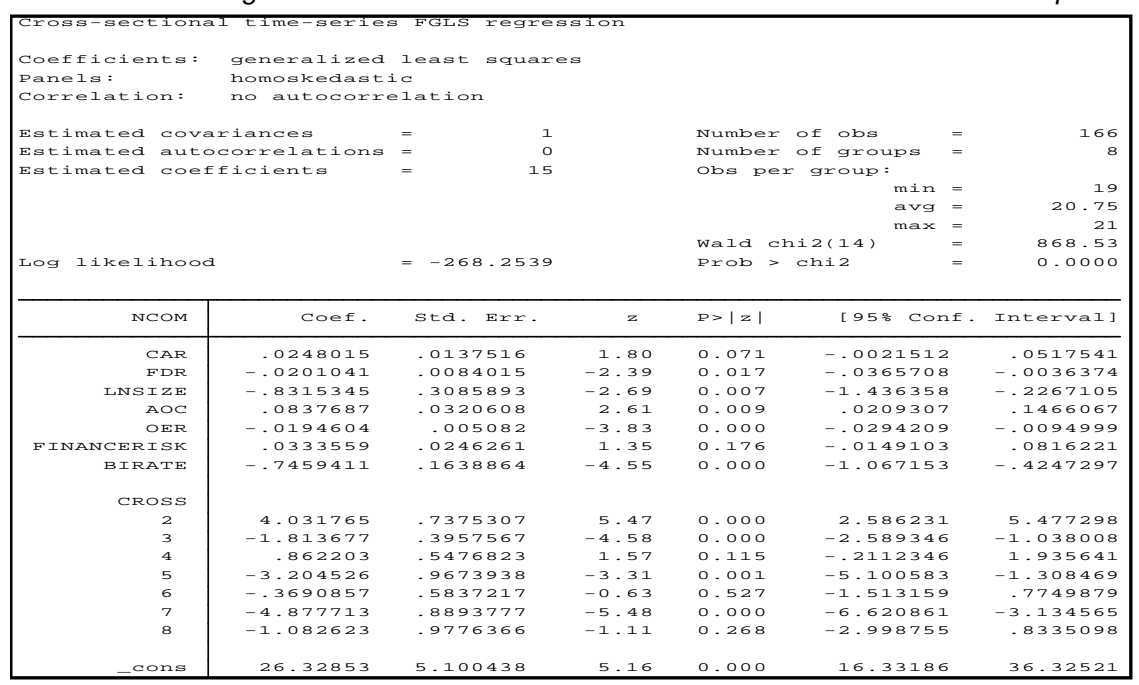

Sumber: Eviews

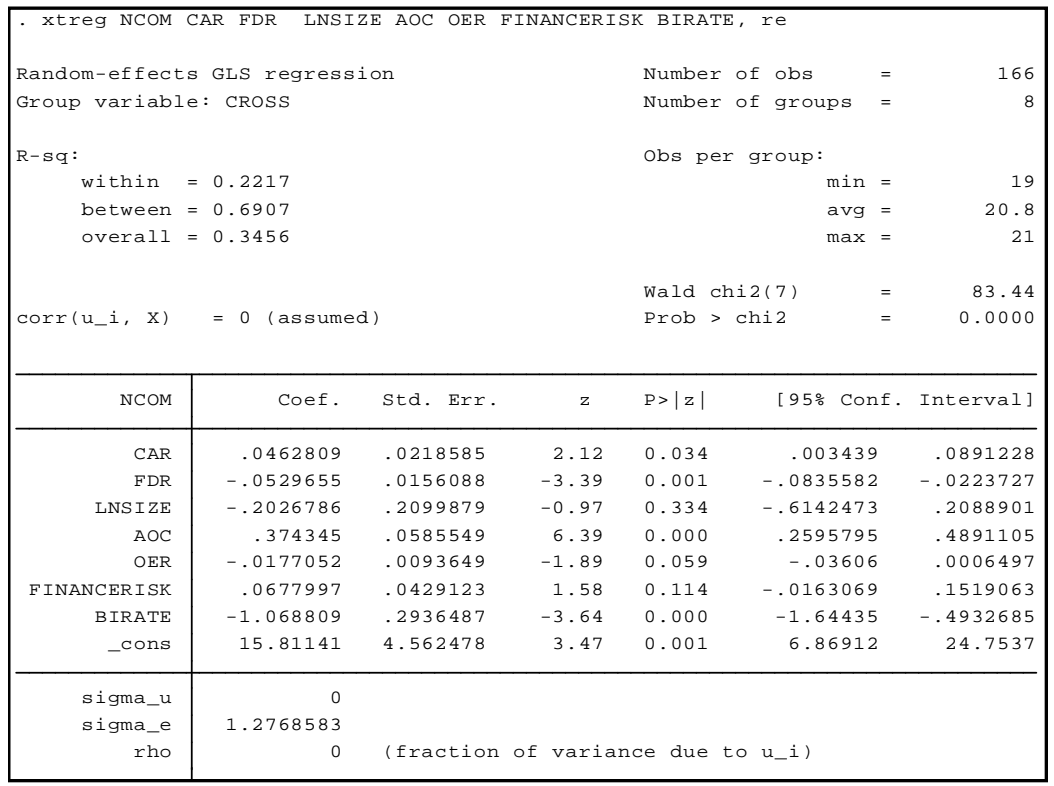

Sumber: Eviews

Pengaruh Capital A dequacy Ratio (CAR) terhadap Tingkat $\mathrm{N}$ et $\mathrm{Core} O$ perational $\mathrm{M}$ argin 
Variabel CAR memberikan hasil estimasi koefisien positif sesuai dengan hipotesis awal. Hasil ttest menunjukan bahwa variabel CAR memiliki pengaruh yang signifikan terhadap tingkat net core operational margin (Maudos \& Guevara, 2004; dan Sidabalok \& Viverita, 2009). Nilai koefisien regresi variabel CAR yaitu 0,0248 , hal ini menunjukan bahwa ketika capital adequacy ratio mengalami kenaikan sebesar $1 \%$, ceteris paribus, tingkat net core operational margin pada perbankan syariah akan mengalami kenaikan sebesar 0,0248 \%. Sehingga semakin tinggi risiko yang dihadapi bank, maka CAR yang dicadangkan semakin tinggi untuk mengcover risiko.

Dalam hal ini, semakin enggan bank untuk mengambil risiko, maka bank akan menetapkan tingkat net core operational margin pada tingkat yang lebih tinggi. Bank membutuhkan margin yang lebih besar untuk menutup besarnya biaya dari modal, dibandingkan dengan menyalurkannya dalam pembiayaan. Modal dikenakan pajak ganda karena baik pendapatan bank dan dividen kepada pemegang saham dikenakan pajak sedangkan pendapatan yang harus dibayarkan kepada deposan bank sudah dikurangi untuk tujuan pajak. Dalam kasus ini, bank akan cenderung untuk mengalihkan potensi risiko melalui kebijakan pricing, memindahkan porsi biaya kepada nasabah debitur dan kreditur.

Pengaruh Financing to $\mathrm{D}$ eposit Ratio (FD R) terhadap Tingkat $\mathrm{N}$ et $\mathrm{C}$ ore $\mathrm{O}$ perational $\mathrm{M}$ argin

Variabel FDR yang merupakan perbandingan antara penyaluran dana bank dalam bentuk pembiayaan dengan dana pihak ketiga yang berhasil dikumpulkan bank, rasio ini memberikan hasil estimasi koefisien negatif sesuai dengan tanda hipotesis awal dan hasil t-test menunjukan bahwa variabel ini memiliki pengaruh yang signifikan terhadap variabel terikat tingkat net core operational margin. Berdasarkan hasil regresi diatas, nilai koefisien variabel financing to deposit ratio sebesar 0,0201, artinya ketika variabel FDR mengalami kenaikan sebesar $1 \%$ ceteris paribus, tingkat net core operational margin pada perbankan syariah akan mengalami penurunan sebesar 0,0201 \% dan hasil analisis ini sejalan dengan penelitian A riyanto (2011) dan Fungáčová \& Poghosyan (2011), bahwa FDR signifikan mempengaruhi NCOM dengan arah negatif.

Ketika tingkat FDR semakin tinggi maka akan diikuti dengan tingginya tingkat pengelolaan dan penyaluran pembiayaan, hal ini akan berimplikasi terhadap semakin rendahnya tingkat net core operational margin, karena skala ekonomi dan cakupan ekonomi dalam pengeloaan pembiayaan yang semakin besar. Dengan demikian, biaya operasional terkait pengelolaan portofolio pembiayaan akan semakin murah, sehingga bank tidak perlu menetapkan margin yang tinggi untuk menutup biaya pengel olaan pembiayaan tersebut.

Pengaruh U kuran Bank (LN SIZE) terhadap Tingkat N et Core O perational M argin

Variabel LNSIZE yang merupakan logaritma natural dari total aset bank memberikan hasil estimasi koefisien negatif sesuai dengan tanda hipotesis awal dan hasil t-test menunjukan bahwa variabel ini memiliki pengaruh yang signifikan terhadap variabel terikat NCOM (Maudos \& Guevara, 2004; Fungáčová \& Poghosyan, 2011; Sidabalok \& Viverita, 2009; dan Trinugroho, et al., 2012), bahwa ukuran bank signifikan mempengaruhi NCOM dengan arah negatif. Selajutnya, LNSIZE sebagai penggambaran ukuran bank memiliki pengaruh tertinggi terhadapat tingkat net core operational margin. Nilai koefisien dari variabel ini sebesar -0,8315. Temuan ini menyatakan bahwa ketika variabel LNSIZE mengalami kenaikan sebesar $1 \%$, ceteris paribus, maka tingkat net core operational margin pada perbankan syariah akan mengalami penurunan sebesar 0,8315\%.

Ukuran bank yang diproksi dengan logaritma natural dari total aset menggambarkan jumlah transaksi dalam sebuah bank. Jumlah transaksi yang besar dapat mengurangi frekuensi operasional dan administrasi sehingga mampu mengurangi biaya operasional bank untuk satuan pendapatnnya. Konsep tersebut sejalan dengan teori economies of scale yaitu dengan peningkatan jumlah transaksi 
maka akan mengurangi biaya per unit sehingga dapat mencapai economies of scale yang kemudian mempersempit margin.

Pengaruh Rata-rata Biaya O perasional (AOC) terhadap Tingkat $\mathrm{N}$ et Core 0 perational $\mathrm{M}$ argin

Variabel AOC yang merupakan rasio biaya operasional terhadap total aset memberikan hasil estimasi koefisien positif sesuai dengan tanda hipotesis awal dan hasil t-test menunjukan bahwa variabel ini memiliki pengaruh yang signifikan terhadap variabel terikat NCOM. Lebih lanjut, mengenai besarnya pengaruh AOC terhadap NCOM, dapat dilihat dari nilai koefisien regresi variabel AOC yaitu 0,0837. Hal ini dapat diartikan bahwa ketika AOC sebagai penggambaran rata-rata biaya operasional mengalami kenaikan sebesar $1 \%$, ceteris paribus, tingkat net core operational margin pada perbankan syariah akan mengalami kenaikan sebesar 0,0837\%.

Temuan ini sejalan dengan hasil penelitian yang telah dilakukan oleh Maudos \& Guevara (2004); Doliente, et al (2009); Fungáčová \& Poghosyan (2011); Trinugroho, et al (2012); Islam \& Nishiyama (2015); dan Afanasieff, et al (2012), perusahaan yang beroperasi dengan biaya yang tinggi, membutuhkan margin yang lebih tinggi untuk menutup biaya operasional. Bank dengan biaya operasional yang tinggi akan menetapkan pendapatan pada sisi (suku bunga, dalam bank konvensional) pembiayaan yang tinggi dan pendapatan pada sisi (suku bunga, dalam bank konvensional) deposit yang rendah, sehingga akan menyebabkan membesarnya jarak margin intermediasi. Besarnya jarak margin intermediasi berbanding lurus terhadap tingkat net core operational margin pada perbankan syariah.

Pengaruh O perational Efficiency Ratio (OER) terhadap Tingkat $\mathrm{N}$ et Core $O$ perational $\mathrm{M}$ argin

Variabel OER merupakan varibel yang membandingkan biaya operasional dengan pendapatan operasi onal. Variabel ini menggambarkan kualitas manajemen perbankan dalam mengelola aset agar menghasilkan laba bagi perusahaan. Varibel ini memberikan hasil estimasi koefisien negatif sesuai dengan tanda hipotesis awal dan hasil analisis ini sejalan dengan penelitian Maudos \& Guevara (2004); Sidabalok \& Viverita (2009); Trinugroho, et al (2012); dan Maudos \& Solisa (2009), bahwa operational efficiency ratio dapat memberikan efek signifikan dan mempengaruhi NCOM dengan arah negatif. Hasil t-test menunjukan bahwa variabel ini memiliki pengaruh signifikan terhadap tingkat net core operational margin. Berdasarkan hasil regresi, nilai koefisien variabel operational efficiency ratio sebesar -0,0194, artinya ketika variabel OER mengalami kenaikan sebesar $1 \%$, ceteris paribus, tingkat net core operational margin pada perbankan syariah akan mengalami penurunan sebesar $0,0194 \%$.

Tingginya kualitas manajemen diartikan pada komposisi aset yang selalu menghasilkan laba (profitable) dan rendahnya biaya pada komposisi liabilitas. Naiknya rasio ini menandakan rendahnya kulitas manajemen dalam perbankan, karena lebih besarnya biaya pada komposisi liabilitas dibandingkan pendapatan yang diterima. Semakin tinggi rasio ini berimplikasi terhadap turunnya efisiensi atau kualitas manajemen yang menyebabkan rendahnya tingkat net core operational margin.

Pengaruh Risiko Pembiayaan (FIN A N CERISK) terhadap Tingkat $\mathrm{N}$ et Core 0 perational M argin

Semakin besar ketidakpastian / volatilitas pendapatan yang diharapkan pada pembiayaan dengan risiko gagal bayar (default risk), maka bank akan menetapkan margin lebih tinggi. Bank sebagai lembaga intermediasi akan selalu menghadapi berbagai risiko dalam menjalankan kegiatannya. ketika tingkat penyaluran pembiyaan dari aset yang dimiliki semakin besar, bank akan mengadapi risiko gagal bayar yang berasal dari debitur dan risiko likuiditas karena sewaktu-waktu kreditur dapat menarik kembali dananya.

Variabel FINANCERISK memberikan hasil estimasi koefisien positif sesuai dengan tanda hipotesis awal. Hasil t-test menunjukan bahwa variabel ini tidak memiliki pengaruh yang signifikan terhadap tingkat net core operational margin. Hasil serupa juga ditunjukan pada Zhou and Wong (2008) pada sektor perbankan di Cina. Penulis berasumsi tidak signifikannya rasio ini secara statistik 
disebabkan perbandingan antara total pembiayaan dengan total aset yang merupakan proksi dari variabel FINANCERISK kurang mewakili risiko gagal bayar yang dihadapi bank.

Pengaruh Tingkat BI Rate (BIRATE) terhadap Tingkat $\mathrm{N}$ et $\mathrm{C}$ ore 0 perational $\mathrm{M}$ argin.

Ketika suku bunga pasar uang meningkat, bank syariah tidak dapat mengatur secara cepat pricing/ penentuang bebasnya fee atau margin pada pembiayaan yang telah mereka salurkan. Karena ketika menaikan besarnya fee atau margin/ pricing pada sisi pembiayaan yang telah disalurkan, bank syariah akan melanggar aturan syariah. Disisi lain, ketika suku bunga pasar meningkat, untuk mencegah para deposan mengalihkan dananya, bank syariah harus meningkatkan keuntungan/ margin pada sisi funding/ liabilitas mereka. Oleh karena itu naiknya suku bunga pasar uang dalam bentuk BI Rate akan menyebabkan beban pendanaan (cost of fund) ikut meningkat, hal ini menyebabkan tingkat net core operational margin menurun.

Variabel BIRATE merupakan suku bunga kebijakan yang mencerminkan sikap atau stance kebijakan moneter yang ditetapkan oleh Bank Indonesia. Variabel ini memberikan hasil estimasi koefisien negatif sesuai dengan tanda hipotesis awal (Hutapea \& Kasri, 2010). Hasil t-test menunjukan bahwa variabel ini memiliki pegaruh signifikan terhadap variabel terikat tingkat net core operational margin. Selajutnya, BIRATE memiliki pengaruh tertinggi kedua terhadapat tingkat net core operational margin. Nilai koefisien dari variabel ini sebesar $-0,7459$. Temuan ini menyatakan bahwa ketika variabel BIRATE mengalami kenaikan sebesar $1 \%$, ceteris paribus, maka tingkat net core operational margin pada perbankan syariah akan mengalami penurunan sebesar $0,7459 \%$.

Bank Indonesia menetapkan suku bunga kebijakan BI Rate sebagai instrumen kebijakan utama untuk mempengaruhi aktivitas kegiatan perekonomian dengan tujuan akhir pencapaian inflasi. Sasaran operasional kebijakan moneter melalui penetapan suku bunga acuan BI Rate, dicerminkan pada perkembangan suku bunga Pasar Uang Antar Bank Overnight (PUAB O/ N). Pergerakan PUAB ini diharapkan akan diikuti oleh perkembangan di suku bunga deposito, dan pada gilirannya suku bunga kredit perbankan. Ketika suku bunga pasar uang meningkat, bank syariah tidak dapat mengatur secara cepat pricing/ penentuan besarnya fee atau margin pada pembiayaan yang telah mereka salurkan. Karena ketika menaikan besarnya fee atau margin/ pricing pada sisi pembiayaan yang telah disalurkan, bank syariah akan melanggar aturan syariah. Disisi lain, ketika suku bunga pasar meningkat, untuk mencegah para deposan mengalihkan dananya, bank syariah harus meningkatkan keuntungan/ margin pada sisi funding/liabilitas mereka. Oleh karena itu naiknya suku bunga pasar uang dalam bentuk BI Rate akan menyebabkan beban pendanaan (cost of fund) ikut meningkat, hal ini menyebabkan tingkat net core operational margin menurun.

Tabel 2. Hasil Regresi dan Hi potesa A wal

\begin{tabular}{|l|l|l|l|l|}
\hline Variabel & $\begin{array}{l}\text { A rah } \\
\text { Regresi }\end{array}$ & P -value & $\begin{array}{l}\text { Hipotesa } \\
\text { Awal }\end{array}$ & Keterangan \\
\hline CAR & Positif & 0.071 & Positif & $\begin{array}{l}\text { Signifikan, sesuai dengan hasil penelitian } \\
\text { arah sama sesuai dengan penelitian Maudos \& } \\
\text { Guevara (2004); Fungáčová \& Poghosyan (2011); dan } \\
\text { Sidabalok \& Viverita (2009). }\end{array}$ \\
\hline FDR & Negatif & 0.017 & Negatif & $\begin{array}{l}\text { Signifikan, arah sama sesuai dengan penelitian } \\
\text { Fungáčová \& Poghosyan (2011); dan A riyanto, T } \\
\text { (2011). }\end{array}$ \\
\hline LNSIZE & Negatif & 0.007 & Negatif & $\begin{array}{l}\text { Signifikan, arah sama sesuai dengan penelitian } \\
\text { Maudos \& Guevara (2004); Sidabalok \& Viverita } \\
\text { (2009); Fungáčová \& Poghosyan (2011); dan } \\
\text { Trinugroho, et al (2012). }\end{array}$ \\
\hline
\end{tabular}




\begin{tabular}{|l|l|l|l|l|}
\hline AOC & Positif & 0.009 & Positif & $\begin{array}{l}\text { Signifikan, arah sama sesuai dengan penelitian } \\
\text { Maudos \& Guevara (2004); Doliente, et al (2009); } \\
\text { Fungáčová \& Poghosyan (2011); Trinugroho, et al } \\
\text { (2012); Islam \& N ishiyama (2015); dan A fanasieff, et al } \\
\text { (2012). }\end{array}$ \\
\hline OER & Negatif & 0.000 & Negatif & $\begin{array}{l}\text { Signifikan, arah sama sesuai dengan penelitian } \\
\text { Maudos \& Guevara (2004); Sidabalok \& Viverita } \\
\text { (2009); Trinugroho, et al (2012); dan Maudos \& Sol isa } \\
\text { (2009). }\end{array}$ \\
\hline FINANCERISK & Positif & 0.179 & Positif & $\begin{array}{l}\text { Tidak signifikan, arah sama sesuai dengan penelitian } \\
\text { Zhou and Wong (2008) }\end{array}$ \\
\hline BIRATE & Negatif & 0.000 & Negatif & $\begin{array}{l}\text { Signifikan, arah sama sesuai dengan penelitian } \\
\text { Hutapea \& Kasri (2010). }\end{array}$ \\
\hline
\end{tabular}

Sumber : Data diolah (2019)

\section{Kesimpulan}

Berdasarkan hasil analisis dan pembahasan dalam model penelitian ini, maka kesimpulan dari penelitian ini adalah bahwa komponen dari Capital A dequacy Ratio, Financing to D eposit Rasio, Ukuran bank, Rata-rata biaya operasional, Kualitas Manajemen, Risiko Pembiayaan dan tingkat suku bunga memiliki pengaruh yang berarti terhadap tingkat $\mathrm{N}$ et Core 0 perational $\mathrm{M}$ argin perbankan syariah di Indonesia. Dan, keseluruhan variabel internal dan eksternal secara bersama-sama memiliki pengaruh yang signifikan terhadap tingkat net core operational. A kan tetapi dalam variabel internal dan eksternal periode penelitian, terdapat perbedaan dalam tingkat signifikansi dalam mempengaruhi $\mathrm{N}$ et Core O perational M argin perbankan syariah di Indonesia.

Implikasi

Tingkat net core operational margin merupakan sumber pendapatan utama bagi perbankan syariah, ketidakstabilan suku bunga pasar uang akan memberikan dampak negatif terhadap profitablitas dan ketahanan perbankan syariah. Oleh karena itu, Bank Indonesia sebagai otoritas moneter, Otoritas Jasa Keuangan sebagai otoritas perbankan dan Pemerintah harus senantiasa menjaga kestabilan pasar dan perekonomian secara keseluruhan agar pertumbuhan perbankan syariah di Indonesia selalu terjaga. Selanjutnya manajemen perbankan perlu menciptakan sistem perbankan yang efisien dengan mengurangi biaya operasional dan meningkatkan kualitas manajemen.

Saran Untuk Penelitian M endatang

Sektor perbankan syariah agar memperluas aspek pasar, ukuran bank yang digambarkan dalam total asset, dimana akan semakin besar sehingga jumlah transaksi yang lebih besar dapat mengurangi frekuensi operasional dan administrasi sehingga mampu mengurangi biaya operasional bank untuk satuan pendapatnnya dan pada akhirnya akan mempersempit margin intermediasi. Perbankan juga disarankan dapat meningkatkan prinsip kehati-hatian pada pengelolaan pembiayaan, agar risiko terjadinya gagal bayar dapat diminimalisir. Dan, untuk riset mendatang, perlu ditambahkan faktorfaktor determinan dalam mengembangkan perbankan khususnya sektor syariah dengan cakupan penelitian lebih diperluas seperti menggunakan rasio non performing financing dan/ atau perbandingan antara penyisihan penghapusan aktiva produktif (PPAP) terhadap total aset sebagai proksi dari variabel risiko pembiayaan (FINANCERISK). 


\section{Referensi}

Afanasieff, T. S., Lhacer, P. M., \& Nakane, M. I. (2002). The determinants of bank interest spread in Brazil. M oney affairs, 15(2), 183-207.

Akbar, M. T. (2012). Analisis Pengaruh Faktor Internal dan Eksternal Bank Terhadap N on Performing Loans Bank Umum Tbk di Indonesia Periode 2007-2011. Tesis. Fakultas Ekonomi Universitas Indonesia, Jakarta.

Ariyanto, T. (2017). Faktor Penentu Net Interest Margin Perbankan Indonesia. Jurnal Keuangan dan Perbankan, 13(1).

Ascarya, A., \& Yumanita, D. (2010). Determinants of bank's net interest margin in Indonesia. In International Conference on Eurasian Economies.

Cooper, D., dan Emory, C. (1997). M etode Pen elitian B isnis Jilid 1. Jakarta: Erlangga.

Demirgüç-Kunt, A., \& Huizinga, H. (1999). Determinants of commercial bank interest margins and profitability: some international evidence. The W orld Bank Economic Review, 13(2), 379-408.

Doliente, J. S. (2003). Determinanats of Bank Net Interst Margin of Southest Asia. Journal University of Limoges France dan University of Philippines.

Dumicic, M., \& Ridzak, T. (2012). Determinants of Banks' Net Interest Margins in CEE. In The eighteenth Dubrovnik E conomic Conference, organized by Croatian N ational Bank.

Fungáčová, Z., \& Poghosyan, T. (2011). Determinants of bank interest margins in Russia: Does bank ownership matter?. Economic systems, 35(4), 481-495.

Hutapea, E. G., \& Kasri, R. A. (2010). Bank margin determination: a comparison between Islamic and conventional banks in Indonesia. International Journal of Islamic and M iddle Eastern Finance and $M$ anagement, 3(1), 65-82.

Islam, M. S., \& Nishiyama, S. I. (2016). The determinants of bank net interest margins: A panel evidence from South Asian countries. Research in International Business and Finance, 37, 501-514.

Levine, R. (1997). Desarrollo financiero y crecimiento económico: puntos de vista y agenda. The Economic J ournal, 35(2), 688-726.

Maudos, J., \& Solís, L. (2009). The determinants of net interest income in the Mexican banking system: An integrated model. Journal of Banking \& Finance, 33(10), 1920-1931.

Maudos, J., \& De Guevara, J. F. (2004). Factors explaining the interest margin in the banking sectors of the European Union. Journal of Banking \& Finance, 28(9), 2259-2281.

Otoritas Jasa Keuangan Republik Indonesia. (2014). Laporan Triwulan I - 2014. Jakarta: Otoritas Jasa Keuangan Republik Indonesia.

Otoritas Jasa Keuangan Republik Indonesia. (2015). Statistik Perbankan Syariah Edisi Juni 2015. Departemen Perizinan dan Informasi Perbankan. Jakarta: Otoritas Jasa Keuangan Republik Indonesia.

Trinugroho, I., Agusman, A., \& Tarazi, A. (2014). Why have bank interest margins been so high in Indonesia since the 1997/ 1998 financial crisis?. Research in International Business and Finance, 32, 139-158.

Ugur, A., \& Erkus, H. (2010). Determinants of the net interest margins of banks in Turkey. Journal of Economic and Social Research, 12(2), 101.

Undang-undang Republik Indonesia N omor 10 Tahun 1998 Tentang perubahan Atas Undang-undang Nomor 10 Tahun 1992 Tentang Perbankan.

Undang-undang Republik Indonesia Nomor 21 Tahun 2008Tentang Perbankan Syariah.

Warganegara, A. R. P. (2011). Determinan Net Interest Margin Industri Perbankan Indonesia. Tesis: Fakultas Ekonomi Universitas Indonesia.

Zhou, K., \& Wong, M. C. (2008). The determinants of net interest margins of commercial banks in mainland China. Emerging M arkets Finance and Trade, 44(5), 41-53. 